INDO GLOBAL JOURNAL OF

PHARMACEUTICAL SCIENCES

ISSN 2249- 1023

\title{
Biochemical Evaluation of Pre and Post Delivery Melasma Patients and Their Clinical Findings
}

\author{
Shweta Katiyar \\ Department of Biochemistry, G.R. Medical College, Gwalior (M.P)-474001, India \\ Address for Correspondance: Shweta Katiyar, shwetakatiyar@gmail.com
}

Keywords

Melasma;

Hyperpigmentation

Disorder;

Antioxidants; Free

Radicals.

\begin{abstract}
Melasma is a common acquired hyperpigmentary disorder that occurs mostly in women thirty years and old, (more than $90 \%$ of cases), of all racial and ethnic groups, and about $10 \%$ in men. The exact etiopathogenesis of Melasma is unknown, although multiple factors have been implicated. These include genetic predisposition, ultraviolet exposure and most notably hormonal influences. In the present study, 69 age and sex matched subjects were taken. These all subjects were females between the age group of 20-35 years, having pre and post pregnancy conditions. The detailed history regarding menstrual cycle, pregnancy, sun exposure and hormonal balances were taken in all the subjects. The skin samples were collected and further SOD (superoxide dismutase), CAT (Catalase), GSH (Reduced glutathione), GPx (Glutathione peroxidase), MDA (Melondialdehyde) and Uric acid levels were studied, where GSH and SOD show the decreased level in age matched individuals and CAT, GPx, MDA and Uric acid were significantly increased.@ 2016 iGlobal Research and Publishing Foundation. All rights reserved.
\end{abstract}

Conference Proceedings: International Conference on Advances in Plant and Microbial Biotechnology (PMB-2017); JIIT, Noida: February 02-04, 2017

Indo Global Journal of Pharmaceutical Sciences( ISSN 22491023 ; CODEN- IGJPAI; NLM ID: 101610675) indexed and abstracted in EMBASE(Elsevier), SCIRUS(Elsevier),CABI, CAB Abstracts, Chemical Abstract Services(CAS), American Chemical Society(ACS), Index Copernicus, EBSCO, DOAJ, Google Scholar and many more. For further details, visit http://iglobaljournal.com 